\title{
Miscellany
}

\section{Neuroleptic malignant syndrome (NMS) database - UK}

Dr D. Kohen and Dr M. Bristow have established a database of cases with a diagnosis of neuroleptic malignant syndrome. The database is named NMS - dbase UK. The aim is to have a record of possible and probable cases, to establish fatality and reversibility of NMS in clinical practice, and to find any significant factors leading to this potentially dangerous disorder. Both psychiatrists will be available to discuss cases, respond to any queries about diagnosis and treatment, management of NMS and rechallenge with neuroleptics. For further information and discussion: Dr D. Kohen, East Wing, Homerton Hospital, Homerton Row, London E9 6SR (Telephone: 01815108115 , fax: 0181510 8716, e-mail: Dora @kohen.freeserve.co.uk) or Dr M. Bristow, Cheam Resource Centre, 669-671 London Road, North Cheam, Surrey SM3 9DL (Telephone: 0181335 4066, fax: 01813354041 , e-mail: mbristow@globalnet.co.uk).

\section{New publications}

Clinical Research in Psychiatry by Stephen Curran and Christopher Williams is a new title from Heinemann Publishers, Oxford. This practical guide is for trainee psychiatrists who are new to the field of research. It provides advice on how to make the research process easier. techniques to help with common problems in carrying out research, and step-by-step practical information on how to carry out research. Priced at $£ 17.99$ copies can be ordered from: Customer Services Department, Heinemann Publishers Oxford, PO Box 382, Halley Court, Jordan Hill, Oxford OX2 8RU (Telephone: 01865 314301, fax: 01865 314029).
To mark the beginning of the 1999 International Year of Older Persons, Age Concern England has issued the updated Age and Race: Double Discrimination and produced a new complementary resource pack entitled Developing Services With and For Minority Ethnic Older People. The former is designed to highlight the disparity between the rapidly growing numbers of minority ethnic older people and the services which are designed to meet their needs, while the latter suggests good practice and ways in which organisations can ensure that their activities are relevant and successful. Priced at $£ 5$ and £2.50 respectively, including postage and packaging, copies are avallable from the Age Concern mail order department (Telephone: 0181765 7203).

Action on Elder Abuse is launching a new series of booklets giving detailed information to medical and social care professionals about preventing and responding to the mistreatment of older people. The booklets are comprehensively written to take account of differing legislation and administrative structures in England, Wales, Scotland and Northern Ireland. Written in conjunction with key professional organisations in the different fields, the three new titles cover The Abuse of Older People: Information for Doctors, The Abuse of Older People in Hospital: Information for Workers and The Abuse of Older People in Residential and Nursing Homes: Information for Workers. Each booklet covers a series of issues, such as the nature of abuse and who may abuse. how to prevent situations where abuse may occur, and when and how to involve the police in cases of suspected abuse. Coples of the booklets can be obtained from Action on Elder Abuse at £2 each (Telephone: 0181764 7648). 